\title{
Myostatin as a mediator of sarcopenia versus homeostatic regulator of muscle mass: insights using a new mass spectrometry-based assay
}

H. Robert Bergen $\mathrm{II}^{1,2 \dagger}$, Joshua N. Farr ${ }^{3,4 \dagger}$, Patrick M. Vanderboom², Elizabeth J. Atkinson ${ }^{5}$, Thomas A. White , Ravinder J. Singh ${ }^{6}$, Sundeep Khosla ${ }^{3,4}$ and Nathan K. LeBrasseur ${ }^{4,7^{*}}$

\begin{abstract}
Background: Myostatin is a protein synthesized and secreted by skeletal muscle that negatively regulates muscle mass. The extent to which circulating myostatin levels change in the context of aging is controversial, largely due to methodological barriers.

Methods: We developed a specific and sensitive liquid chromatography with tandem mass spectrometry (LC-MS/ MS) assay to measure concentrations of myostatin and two of its key inhibitors, follistatin-related gene (FLRG) protein and growth and serum protein-1 (GASP-1) in 80 younger (<40 years), 80 older ( $>65$ years), and 80 sarcopenic older women and men.

Results: Older women had $34 \%$ higher circulating concentrations of myostatin than younger women. Per unit of lean mass, both older and sarcopenic older women had $>23 \%$ higher myostatin levels than younger women. By contrast, younger men had higher myostatin concentrations than older men with and without sarcopenia. Younger men had approximately twofold higher concentrations of myostatin than younger women; however, older women and sarcopenic older women had significantly higher relative myostatin levels than the corresponding groups of men. In both sexes, sarcopenic older subjects had the highest concentrations of FLRG. Circulating concentrations of myostatin exhibited positive, but not robust, correlations with relative muscle mass in both sexes.

Conclusions: Our data suggest that myostatin may contribute to the higher prevalence of sarcopenia in women but acts as a homeostatic regulator of muscle mass in men. Moreover, this new LC-MS/MS-based approach offers a means to determine the extent to which myostatin serves as a biomarker of muscle health in diverse conditions of muscle loss and deterioration.
\end{abstract}

Keywords: Myostatin, Aging, Sarcopenia, Skeletal muscle mass, Strength, Body composition

\section{Background}

Over 50 years ago, circulating tissue-specific growth inhibitors were hypothesized to explain how tissue sizes are controlled [1]. Considerable work has since established growth and differentiation factor (GDF)-8, or myostatin, as a robust negative regulator of skeletal muscle mass. Myostatin is a member of the transforming

\footnotetext{
* Correspondence: lebrasseur.nathan@mayo.edu

${ }^{\dagger}$ Equal contributors

${ }^{4}$ Robert and Arlene Kogod Center on Aging, Mayo Clinic College of

Medicine, Rochester, MN 55905, USA

7Department of Physical Medicine and Rehabilitation, Mayo Clinic College of Medicine, 200 First Street SW, Rochester, MN 55905, USA

Full list of author information is available at the end of the article
}

growth factor $\beta$ (TGF- $\beta$ ) superfamily that is highly enriched in skeletal muscle [2]. It is synthesized as a precursor protein and forms a disulfide-linked homodimer. The signal peptide of the myostatin precursor protein is removed by proteolytic cleavage to form promyostatin $[2,3]$. Furin protein convertases within the Golgi apparatus or the extracellular space cleave promyostatin to generate $\mathrm{N}$ - and $\mathrm{C}$-terminal fragments $[4,5]$, which are bound non-covalently and form a latent myostatin complex. The $\mathrm{N}$-terminal is an inhibitory prodomain, referred to as propeptide, and the $\mathrm{C}$-terminal represents the mature biologically active form of myostatin. The latent complex is disassembled by BMP1/tolloid proteinases [6],

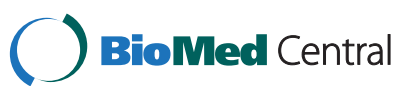


which enables the mature $\mathrm{C}$-terminal dimer to bind to the activin type IIB receptor (ActRIIB). Through ActRIIB and its downstream effectors, particularly Smad2/3, myostatin simultaneously activates protein degradation and inhibits protein synthesis in adult skeletal muscle [7, 8]. As a result, myostatin is a promising therapeutic target for conditions of compromised muscle health, including age-related sarcopenia, disease-associated cachexia, congenital myopathies, muscular dystrophies, disuse atrophy, and trauma.

Despite strong evidence that genetic and pharmacological modulations of myostatin abundance and/or activity impact muscle mass in multiple species [9-13], data on circulating myostatin concentrations in humans are sparse and conflicting. In an early cross-sectional study, serum myostatin levels measured by radioimmunoassay (RIA) were reported to be significantly elevated with advancing age and declining lean mass, suggesting that myostatin may serve as a biomarker of sarcopenia in women and men [14]. While provocative, no subsequent study has been able to corroborate these findings. Indeed, recent studies measuring concentrations in the serum using enzyme-linked immunosorbent assays (ELISAs) have reported either no change or a decline in circulating myostatin levels in older compared to younger persons [15-17]. Of further concern, ELISAbased approaches for measuring circulating myostatin concentrations have yielded highly erratic values for healthy adults, ranging from just over 4 [15] to over 100 [18] and even 32,500 $\mathrm{ng} / \mathrm{ml}$ [19].

The reasons for these inconsistent findings are not clear but likely stem from the complexities of measuring myostatin in clinical samples (reviewed in [20]). In particular, some assays have not fully appreciated the homology between myostatin and other circulating TGF- $\beta$ superfamily members, which can result in crossreactivity. For example, assays for myostatin may not exclude GDF-11, which shares $90 \%$ homology with myostatin in its C-terminal biologically active domain [21]. Lack of specificity has likely contributed to overestimates of serum myostatin levels in several previous studies. The development and use of antibodies with higher affinity and increased specificity for myostatin have undoubtedly improved the accuracy of ELISAbased approaches [15, 17]; however, these proprietary reagents remain unavailable to the broader research community. Antibody-based methods are also limited by relatively low sensitivity. This is an additional challenge to accurately quantify circulating myostatin, which is of relatively low abundance in human serum. It is also important to recognize that the earlier RIA study was performed prior to the discovery that in circulation, myostatin forms a latent complex when bound to its inhibitory proteins, including follistatin-related gene
(FLRG) protein and growth and serum protein-1 (GASP-1) [22, 23]. Only one study has provided insight into how these proteins may change in relation to age, muscle mass, and myostatin, and it was limited to men [15]. Moreover, as reviewed above, the N-terminal propeptide also inhibits myostatin activity. However, current approaches used to measure circulating myostatin concentrations are often unable to distinguish between latent and mature forms. Collectively, these methodological limitations have hindered progress in understanding how myostatin may change in humans in the context of health, aging, and disease and serve as a biomarker for skeletal muscle mass.

To overcome these challenges, we developed a multiplexed assay combining immunoaffinity purification, liquid chromatography with tandem mass spectrometry (LC-MS/MS), and selected reaction monitoring (SRM) to specifically and accurately measure tryptic peptides from both the mature and propeptide regions of circulating myostatin and two of its inhibitory proteins, FLRG and GASP-1. We then applied this novel approach to a well-characterized, population-based sample to determine the extent to which circulating concentrations of myostatin and its inhibitory proteins change within women and men across adulthood, compare between women and men, and associate with skeletal muscle mass.

\section{Methods}

\section{Study subjects}

Study subjects were selected from a random sample of the population of Rochester, MN, USA, using the Rochester Epidemiology Project medical records linkage system as previously described [24]. A total of 240 subjects who met the study inclusion criteria were studied, including 120 women and 120 men. Within each sex, 40 younger (20-40 years old) and 80 older ( $\geq 65$ years old) subjects were included. The older women and older men were then each divided into two groups of 40 subjects based on their relative appendicular skeletal muscle mass (rASM). All 40 of the older women and 34 of the older men with comparatively low rASM were below the cut-offs recently suggested for sarcopenia, which are $\leq 5.67$ and $\leq 7.23 \mathrm{~kg} / \mathrm{m}^{2}$ for women and men, respectively [25]. The three groups within each sex are herein referred to as younger, older, and sarcopenic. The Mayo Clinic Institutional Review Board approved this study, and all participants provided written informed consent.

Subjects were rigorously screened for coexisting disease using clinical records, and a health history and complete list of medications were obtained during an interview. This study only included subjects without the presence of coexisting disease and excluded postmenopausal women on hormone replacement therapy but not 
younger women on oral contraceptives. Individuals on medications associated with altered skeletal muscle mass or function were also excluded. Menopause was defined as the absence of menses for greater than 6 months. Using this definition, all of the younger women were premenopausal, whereas all older women were postmenopausal. All data, including serum samples, were collected in the outpatient Mayo Clinical Research Unit between November of 2000 and May of 2006. Blood samples were collected from study subjects the morning following an overnight fast and were stored at $-80{ }^{\circ} \mathrm{C}$.

\section{Study protocol}

Height was obtained (nearest millimeter) using a wallmounted stadiometer (Mayo Section of Engineering) and weight obtained (nearest $0.1 \mathrm{~kg}$ ) using an electronic scale (Model 5002, Tronic, Inc., White Plains, NY, USA). Body mass index $\left(\mathrm{BMI}, \mathrm{kg} / \mathrm{m}^{2}\right)$ was calculated as the ratio of weight to height squared. Total body and regional measures of lean mass $(\mathrm{kg})$ and fat mass $(\mathrm{kg})$ were obtained from whole-body dual-energy X-ray absorptiometry (DXA) scans (Lunar Prodigy, GE Medical Systems, Madison, WI, USA), using software version 6.10.029. The coefficient of variation $(\mathrm{CV})$ for whole-body lean mass $(\mathrm{CV}=0.6 \%)$ has been reported previously [26].

Grip strength $(\mathrm{kg})$ and knee extensor strength $(\mathrm{kg})$ were assessed quantitatively with dynamometers (NK Biotechnical Corp., Minneapolis, MN, USA). Estimates of caloric expenditure $(\mathrm{kcal} / \mathrm{d})$ based on habitual levels of physical activity over the preceding year were calculated using data obtained from a validated physical activity questionnaire [27] and were adjusted for body weight as described previously [26]. Each activity was assigned a published metabolic equivalent (MET [1 MET $=3.5 \mathrm{~mL}$ $\left.\mathrm{O}_{2} \times \mathrm{kg}^{-1} \times \mathrm{min}^{-1}\right]$ ) value obtained from the compendium of physical activities [28].

\section{Materials}

Tris(2-carboxyethyl)phosphine hydrochloride (TCEP) and iodoacetamide were purchased from Sigma (St. Louis, MO, USA). Phosphate buffered saline (PBS) was purchased from Bio-Rad (Hercules, CA, USA). Ammonium bicarbonate was purchased from J.T. Baker (Center Valley, PA, USA). 3-[(3-cholamidopropyl)dimethylammonio]-1-propanesulfonate (CHAPS), bovine serum albumin (BSA), and trifluoroacetic acid (TFA) was purchased from Thermo Fisher Scientific (Waltham, MA, USA). Zwittergent Z3-16 was purchased from CalBiochem (EMD Millipore, Billerica, MA, USA). Dynabeads ${ }^{\circ}$ M-280 Streptavidin was purchased from Invitrogen (Carlsbad, CA, USA). Trypsin/Lys-C Mix was purchased from Promega (Madison, WI, USA). Recombinant human myostatin (cat\# 4623-10) was purchased from Biovision (Milpitas, CA, USA). Recombinant human GASP-1 (cat\# 2070-GS-
025), recombinant human FLRG (cat\# 1288-F3-025), biotinylated anti-myostatin antibody (cat\# BAF788), biotinylated anti-GASP1 antibody (cat\# BAF2070), and biotinylated anti-FLRG antibody (cat\# BAF1288) were purchased from R\&D systems (Minneapolis, MN, USA).

\section{Magnetic bead preparation}

Biotinylated anti-myostatin, biotinylated anti-GASP-1, and biotinylated anti-FLRG antibodies $(0.25 \mu \mathrm{g} / \mu \mathrm{L}$ in PBS with $0.1 \%$ BSA) were each immobilized to Dynabeads $^{\circ} \mathrm{M}-280$ Streptavidin (10 $\mathrm{mg} / \mathrm{mL}$ in PBS) at a ratio of $40 \mu \mathrm{L}$ antibody to $125 \mu \mathrm{L}$ of magnetic bead suspension. These solutions were then combined, washed three times with PBS, and reconstituted to a final volume of $625 \mu \mathrm{l}$ with PBS.

\section{Sample preparation}

Standards, controls, and patient samples $(400 \mu \mathrm{L})$ were each transferred into $1.5-\mathrm{mL}$ microcentrifuge tubes and diluted with $600 \mu \mathrm{L}$ PBS containing $0.03 \%$ CHAPS. Fifteen microliters of the immobilized antibody mixture (0.25 $\mu \mathrm{g}$ of each antibody) was added to each microcentrifuge tube containing sample or standards and incubated overnight at $4{ }^{\circ} \mathrm{C}$ with rotation. The beads were washed three times with $500 \mu \mathrm{L}$ PBS, and the PBS was removed before adding $15 \mu \mathrm{L}$ of $8 \mathrm{M}$ urea, $15 \mathrm{mM}$ TCEP in $50 \mathrm{mM}$ ammonium bicarbonate. Synthetic internal standard peptides were synthesized in the Mayo Proteomics Core. Some target peptides were prepared as extended tryptic sequence containing four to five additional amino acids at both the $\mathrm{N}$ - and $\mathrm{C}$-terminal ends to take into account digestion efficiencies as noted in Table 1. The internal standard peptide mixture $(5 \mu \mathrm{M}$ IIYGKIPAMV*VDRCGCS, $2.5 \mu \mathrm{M}$ AGVLRADFPLSV*VRGHQAA, $12.5 \mu \mathrm{M}$ GLPARLQVCGSD*G*ATYRDECEL, and $0.625 \mu \mathrm{M}$ EQ*IIYGK, VSELTEE*PDSGR) in $50 \mathrm{mM}$ ammonium bicarbonate $(5 \mu \mathrm{L})$ was added and the samples incubated for $30 \mathrm{~min}$ at room temperature (RT). Following reduction, samples were alkylated with $20 \mu \mathrm{L}$ of $60 \mathrm{mM}$ iodoacetamide (30 mM final) and incubated in darkness for $30 \mathrm{~min}$ at RT. Subsequently, the urea was diluted to $1.1 \mathrm{M}$ urea with the addition of $70 \mu \mathrm{L}$ of $50 \mathrm{mM}$ ammonium bicarbonate. Finally, $5 \mu \mathrm{L}$ of $0.2 \mu \mathrm{g} / \mu \mathrm{L}$ Tryp$\sin /$ Lys-C Mix was added directly to digest all bead bound protein after incubation at $37^{\circ} \mathrm{C}$ for $4 \mathrm{~h}$. The digestion was terminated by adding $5 \mu \mathrm{L}$ of $4.7 \%$ TFA with $0.02 \%$ Zwittergent ${ }^{\circ} 3-16$, and the digest was removed to an autosampler vial after separation from the beads prior to LCMS/MS analysis.

\section{Liquid chromatography-tandem mass spectrometry}

LC-MS/MS was performed using a nanoAcquity UPLC system (Waters Corporation, Milford, MA, USA) plumbed with a vented tee and coupled to a TSQ Vantage triple 
Table 1 Peptides, transitions, and instrument parameters for myostatin, propeptide, GASP-1, and FLRG

\begin{tabular}{|c|c|c|c|c|}
\hline & $\begin{array}{l}\text { Parent } \\
\text { mass }\end{array}$ & $\begin{array}{l}\text { Product } \\
\text { mass }\end{array}$ & $\begin{array}{l}\text { Collision } \\
\text { energy }\end{array}$ & S-lens \\
\hline \multicolumn{5}{|l|}{ Myostatin } \\
\hline \multirow[t]{3}{*}{ IPAMVVDR } & 450.68 & 619.33 & 19 & 123 \\
\hline & 450.68 & 690.40 & 17 & 123 \\
\hline & 450.68 & 787.52 & 17 & 123 \\
\hline \multirow[t]{3}{*}{ ॥YGKIPAMV*VDRCGCS } & 453.65 & 619.44 & 19 & 123 \\
\hline & 453.65 & 690.50 & 18 & 123 \\
\hline & 453.65 & 763.65 & 16 & 123 \\
\hline \multirow[t]{2}{*}{ EQIIYGK } & 425.66 & 480.31 & 13 & 86 \\
\hline & 425.66 & 593.47 & 14 & 86 \\
\hline \multirow[t]{2}{*}{$E Q^{*} \| Y G K$} & 429.14 & 480.35 & 13 & 86 \\
\hline & 429.14 & 600.43 & 14 & 86 \\
\hline \multicolumn{5}{|l|}{ Propeptide } \\
\hline \multirow[t]{3}{*}{ TVLQNWLK } & 501.18 & 560.32 & 18 & 131 \\
\hline & 501.18 & 688.60 & 18 & 131 \\
\hline & 501.18 & 801.78 & 18 & 131 \\
\hline \multirow[t]{3}{*}{ SIDVKTVLQNW*LKQPESN } & 504.75 & 567.25 & 19 & 131 \\
\hline & 504.75 & 695.42 & 17 & 131 \\
\hline & 504.75 & 808.65 & 15 & 131 \\
\hline \multirow[t]{3}{*}{ ELIDQYDVQR } & 639.70 & 680.42 & 21 & 132 \\
\hline & 639.70 & 808.50 & 20 & 132 \\
\hline & 639.70 & 923.77 & 20 & 132 \\
\hline \multirow[t]{3}{*}{ ELIDQYD*VQR } & 642.92 & 686.48 & 20 & 132 \\
\hline & 642.92 & 814.36 & 22 & 132 \\
\hline & 642.92 & 929.43 & 21 & 132 \\
\hline \multicolumn{5}{|l|}{ GASP-1 } \\
\hline ADFPLSVVR & 502.28 & 670.53 & 18 & 131 \\
\hline \multirow[t]{2}{*}{ AGVLRADFPLSV*VRGHQAA } & 505.23 & 579.46 & 19 & 131 \\
\hline & 505.23 & 676.64 & 16 & 131 \\
\hline \multirow[t]{2}{*}{ VSELTEEPDSGR } & 659.81 & 789.36 & 20 & 168 \\
\hline & 659.81 & 890.51 & 21 & 168 \\
\hline \multirow[t]{2}{*}{ VSELTEE*PDSGR } & 662.73 & 795.31 & 21 & 168 \\
\hline & 662.73 & 896.60 & 21 & 168 \\
\hline \multicolumn{5}{|l|}{ FLRG } \\
\hline \multirow[t]{4}{*}{ LQVCGSDGATYR } & 663.78 & 826.30 & 23 & 168 \\
\hline & 663.78 & 986.34 & 21 & 168 \\
\hline & 663.78 & 1085.46 & 21 & 168 \\
\hline & 666.78 & 832.56 & 24 & 168 \\
\hline \multirow{3}{*}{ GLPARLQVCGSD*G*ATYRDECEL } & & & & \\
\hline & 666.78 & 992.69 & 23 & 168 \\
\hline & 666.78 & 1092.15 & 22 & 168 \\
\hline
\end{tabular}

Target peptides for each protein, parent and product ion masses as well as MS parameters and transitions used quantitation of each protein are indicated in bold and/or italics. Labeled amino acids $\left({ }^{13} \mathrm{C}_{5}^{15} \mathrm{~N}-\mathrm{V},{ }^{13} \mathrm{C}_{6}^{15} \mathrm{~N}-\mathrm{L},{ }^{13} \mathrm{C}_{5}^{15} \mathrm{~N}-\mathrm{P}\right.$,

${ }^{13} \mathrm{C}_{2}^{15} \mathrm{~N}-\mathrm{G}$, and ${ }^{13} \mathrm{C}_{3}-\mathrm{A}$ ) are indicated by the asterisk quadrupole mass spectrometer (ThermoScientific, San Jose, CA, USA) with an ADVANCE Captive Spray source (Michrom Bioresources). Briefly, $10 \mu \mathrm{l}$ of digested sample was loaded onto a $0.25 \mu \mathrm{L} \mathrm{OPTI}^{-P_{A K}} \mathrm{~K}^{\circ}$ trap cartridge (Optimize Technologies, Oregon City, OR, USA) packed with Michrom Magic C8 (5 $\mu \mathrm{m}, 200 \mathrm{~A})$ using $0.1 \%$ formic acid in $2 \% \mathrm{ACN}$ at a flow rate of $10 \mu \mathrm{L} / \mathrm{min}$ for $4 \mathrm{~min}$. Following loading, the peptides were eluted onto the analytical column (Michrom, Magic C18 AQ 200 A, $0.1 \times$ $150 \mathrm{~mm}, 3 \mu \mathrm{m})$ with a 20 -min gradient from $98 \% \mathrm{~A}$ $(0.1 \%$ formic acid in $2 \% \mathrm{ACN})$ to $40 \% \mathrm{~B}(0.1 \%$ formic acid in $80 \% \mathrm{ACN}$ and $10 \% \mathrm{IPA}$ ) at $1 \mu \mathrm{L} / \mathrm{min}$. The gradient was taken to $95 \% \mathrm{~B}$ in $3 \mathrm{~min}$ and held for $2 \mathrm{~min}$ at $95 \%$ to wash the column. The column was then equilibrated by returning the gradient to $98 \% \mathrm{~A}$ in $3 \mathrm{~min}$ where it was held for $7 \mathrm{~min}$ for a total run time of $35 \mathrm{~min}$.

LC-MS/MS was performed in positive ion mode using a spray voltage of $1400 \mathrm{~V}$ and a capillary temperature of $175{ }^{\circ} \mathrm{C}$. All tryptic peptides and their corresponding labeled peptides were monitored in the $\left(\mathrm{M}+2 \mathrm{H}^{+}\right)^{2+}$ charge state. Transitions (Additional file 1: Table S1) were monitored in three time segments. Resolution was set at 0.7 FWHM for both Q1 and Q3. The scan time was $20 \mathrm{~ms}$, and the scan width was set at $0.05 \mathrm{Da}$.

\section{Raw data analysis}

Xcalibur Quan Browser version 2.2 was used for data processing. Peak integration was performed with the following parameters: peak detection algorithm, genesis; smoothing, 9; signal to noise threshold, 0.5. Peak areas for each SRM transition were recorded individually, and one transition per peptide was chosen for quantitation (Additional file 1: Table S1). Peak area ratios were established for each surrogate peptide and its corresponding internal standard peptide, and calibration curves were generated by plotting these ratios against protein concentration (nM). Each peptide was fit with a linear calibration curve using $1 / \mathrm{X}$ weighting, with the exception of VSELTEEPDSGR for GASP-1, which was fit with a quadratic curve using $1 / \mathrm{X}$ weighting.

\section{Other biochemical measures}

Total 25-hydroxyvitamin D [25-(OH)D] (inter-assay CV = $7 \%$ ) was measured in serum using LC-MS/MS (API 5000; Applied Biosystems-MDS Sciex, Foster City, CA, USA). Total insulin-like growth factor 1 (IGF-1) and IGF-2 (inter-assay $\mathrm{CVs}=6 \%$ for both) were measured in serum by a two-site immunoradiometric assay (IRMA), after separation from their binding proteins with a simple organic solvent extraction (Diagnostic Systems Laboratories, Webster, TX, USA). Serum insulin-like growth factor binding protein 2 (IGFBP-2) (inter-assay CV $=16 \%$ ) was measured by a double antibody RIA (Diagnostic Systems Laboratories, Webster, TX, USA), whereas IGFBP-3 
(inter-assay $\mathrm{CV}=14 \%$ ) was measured in serum by a twosite IRMA (Diagnostic Systems Laboratories, Webster, TX, USA). Sex hormone-binding globulin (SHBG) (interassay CV $=7 \%$ ) was measured in serum by RIA (Wien Laboratories, Succasunna, NJ, USA) [29]. As described previously [30], serum sex steroids, including estrone $\left(\mathrm{E}_{1}\right.$, inter-assay $\mathrm{CV}=8 \%)$, estradiol $\left(\mathrm{E}_{2}\right.$, inter-assay $\left.\mathrm{CV}=8 \%\right)$, and testosterone ( $\mathrm{T}$, inter-assay $\mathrm{CV}=6 \%$ ) were measured using LC-MS/MS (API 5000; Applied Biosystems-MDS Sciex, Foster City, CA, USA), which allows detection of values as low as $1.25 \mathrm{pg} / \mathrm{mL}$ for both $E_{1}$ and $E_{2}$ and $1 \mathrm{ng} /$ $\mathrm{dL}$ for $\mathrm{T}$. The non-SHBG bound (i.e., biologically active fraction) of $\mathrm{E}_{2}$ and $\mathrm{T}$ (inter-assay $\mathrm{CVs}=12 \%$ for both) were measured and then multiplied by the total $E_{2}$ or $T$ measured by mass spectrometry to obtain the respective bioavailable $\mathrm{E}_{2}$ and $\mathrm{T}$ fractions.

\section{Statistical analysis}

In women and men, separately, comparisons among the younger, older, and sarcopenic groups were made using an analysis of variance model. Comparisons between younger, older and sarcopenic women, and the corresponding group of men were made using an unpaired $t$ test. The Mann-Whitney $U$ test was used when variables were not normally distributed, as appropriate. Associations of myostatin levels with body composition, muscle strength, physical activity, and other biochemical parameters were examined using age-adjusted Spearman correlations. Testing was performed at a significance level of $P<0.05$ (two-tailed). Analyses were performed using JMP 10.0 and SAS 9.3. Box plots (25-75 percentile), and whiskers (Tukey method) were created using GraphPad Prism 5.03.

\section{Results}

Validation of a LC-MS/MS assay for myostatin, GASP-1, and FLRG

The peptides, transitions, and instrument parameters for myostatin, propeptide, GASP-1, and FLRG are detailed in Table 1. The lower limits of detection (LOD, average blank concentration plus 3 SDs) for myostatin, propeptide, GASP-1, and FLRG were 0.01 (0.248), $0.015(0.42)$, 0.01 (0.607), and $0.02 \mathrm{nM}(0.258 \mathrm{ng})$, respectively. The lower limits of quantification (LOQ, three replicates $<20 \%$ CV within $20 \%$ accuracy) for myostatin, propeptide, GASP-1, and FLRG were 0.01 (0.248), 0.015 (0.42), 0.01 (0.607), and $0.02 \mathrm{nM}(0.258 \mathrm{ng})$, respectively. Standard curves for the proteins are presented in Fig. 1. The intra-assay variability between five replicates of myostatin, propeptide, GASP-1, and FLRG at four different concentrations was less than $12,10,8$, and $9 \%$, respectively (Additional file 1: Table S1). The inter-assay variability at different concentrations of myostatin, propeptide, GASP-1, and FLRG was less than 21, 13, 11, and $8 \%$, respectively (Additional file 2: Table S2). The percent recovery of myostatin, FLRG, and GASP-1 spiked into a pooled serum sample ranged from 65 to 88 \% (Additional file 3: Table S3). Collectively, these data validate a specific and sensitive LC-MS/MS method for determination of even very low concentrations of mature and propeptide forms of myostatin and two of its inhibitors in human serum.

\section{Clinical characteristics of the study subjects}

Clinical characteristics of the younger, older, and sarcopenic groups are shown in Table 2, and biochemical parameters are shown in Table 3, stratified by sex. As designed, sarcopenic older women and men had significantly less lean mass (both relative appendicular skeletal muscle mass (ASM) and total body lean mass (TBLM), all $p<0.05$ ) and lower grip and knee extension strength than younger and older subjects of the same sex (all $p<$ 0.05). Further, younger, older and older sarcopenic men had greater lean mass (both relative ASM and TBLM; all $p<0.001)$ than the corresponding group of women. In fact, the sarcopenic older men not only had greater lean mass than sarcopenic older women but also had greater lean mass than both the younger and older groups of women (Table 1). Consequently, in addition to using absolute circulating myostatin concentrations in our analyses, we calculated and used relative myostatin and propeptide concentrations by normalizing to TBLM. This facilitated interpretation of myostatin and propeptide concentrations within the context of a given amount of lean mass.

\section{Circulating concentrations of myostatin and myostatin- related proteins in women and men}

We first compared myostatin, propeptide, FLRG, and GASP-1 within groups of women and men, separately. Compared to younger women, older women had $33 \%$ higher circulating concentrations of myostatin $(p<0.001)$, while sarcopenic older women had comparable levels (Fig. 2a and Table 3). However, for a given amount of TBLM, older women and sarcopenic older women had 40 and $23 \%$ higher relative myostatin concentrations than younger women, respectively (both $p<0.01$; Fig. 2b). Similar patterns were observed for propeptide concentrations (Table 3), namely, older women had $61 \%$ higher absolute concentrations of propeptide than younger women while both older women and sarcopenic older women had 51 and $58 \%$ higher relative propeptide levels than younger women (Fig. 2c, d). There were no differences in the ratio of myostatin to propeptide between the groups (data not shown (DNS)). In contrast, younger men had significantly higher absolute myostatin concentrations than older men without or with sarcopenia (both $p<0.001$; Fig. 2e and Table 3). Of note, the age-associated decrease in 

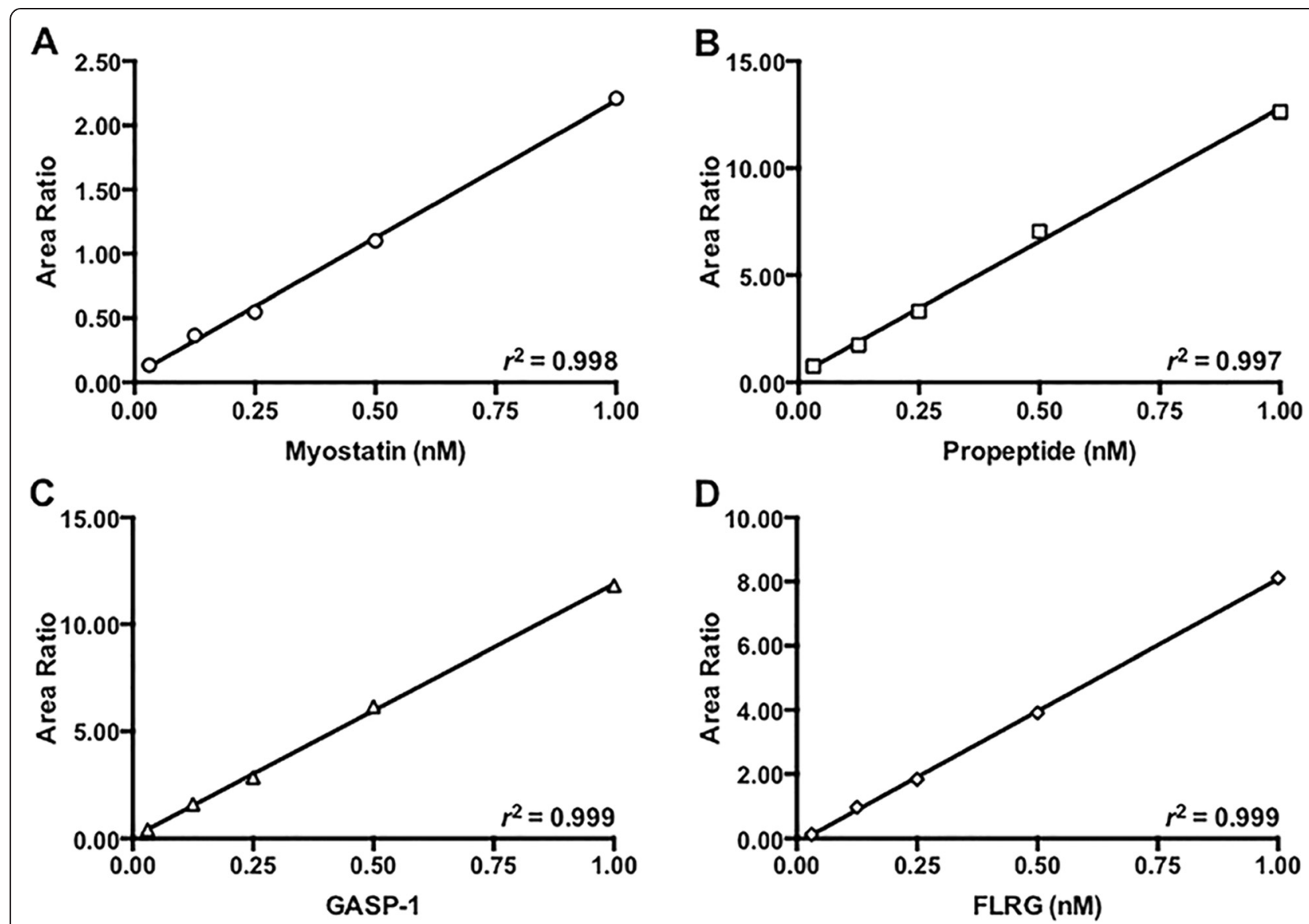

Fig. 1 Calibration curves for LC-MS/MS measures of myostatin, propeptide, GASP-1, and FLRG. Linear calibration curves for recombinant intact myostatin (a), propeptide (b), GASP-1 (c), and FLRG (d) diluted into bovine serum albumin over a concentration range of 0.031 to 1.00 nM

circulating myostatin observed in men was maintained even after normalizing to TBLM, as younger men had at least $25 \%$ higher relative myostatin levels than both groups of older men (both $p<0.01$; Fig. 2f). Propeptide levels were also significantly higher in younger men than sarcopenic older men (Fig. 2g), but no differences were observed between groups after normalizing propeptide concentrations to TBLM (Fig. $2 \mathrm{~h}$ and Table 3). Similar to women, no differences in the ratio of myostatin to propeptide were observed among the groups of men.

We next explored circulating concentrations of two inhibitors of myostatin, FLRG and GASP-1, in all subjects. Compared to younger women, FLRG levels were 43 and $62 \%$ higher in older women and sarcopenic older women, respectively (both $p<0.001$; Fig. 3a and Table 3). GASP-1 changed in a like manner, but differences were only significant between younger women and sarcopenic older women $(p<0.05$; Fig. 3b). We next assessed the ratios of FLRG to myostatin and GASP-1 to myostatin. Sarcopenic older women had the highest ratios of FLRG to myostatin compared to older and younger subjects (Fig. 3c), while a modest decrease in the ratio of GASP-1 to myostatin was observed in older women compared to younger and sarcopenic older women (Fig. 3d). Similar to women, circulating FLRG concentrations were $68 \%$ higher in older men and $64 \%$ higher in sarcopenic older men than in younger men (both $p<0.001$; Fig. 3e and Table 3), but trends for ageassociated increases in GASP-1 were not significant (Fig. 3f). Older men and sarcopenic older men had higher ratios of both FLRG and GASP-1 to myostatin than younger men (all $p<0.001$; Fig. $3 g$, $\mathrm{h}$, respectively). In addition, sarcopenic older men had significantly higher ratios of GASP-1 to myostatin than older men $(p<0.01)$.

Sex differences in circulating concentrations of myostatin and myostatin inhibitors

In separate analyses, we compared myostatin, propeptide, FLRG, and GASP-1 concentrations in women to those in the corresponding group of men. In all subjects combined, circulating myostatin levels were 1.3-fold higher in men than in women (median (interquartile range $(\mathrm{IQR}))=7.8(6.0-10.5)$ versus $6.0(4.3-8.2) \mathrm{ng} / \mathrm{mL}$, $p<0.001)$, even after expressing myostatin relative to 
Table 2 Descriptive characteristics of younger, older, and sarcopenic older women and men $(n=240)$

\begin{tabular}{|c|c|c|c|}
\hline & $\begin{array}{l}\text { Younger } \\
(n=40)\end{array}$ & $\begin{array}{l}\text { Older } \\
(n=40)\end{array}$ & $\begin{array}{l}\text { Sarcopenic } \\
(n=40)\end{array}$ \\
\hline \multicolumn{4}{|l|}{ Women } \\
\hline \multicolumn{4}{|l|}{ Clinical variables } \\
\hline Age (years) & $32.3 \pm 5.5$ & $76.0 \pm 8.6^{*}$ & $78.4 \pm 8.2^{* *}$ \\
\hline Weight (kg) & $69.2 \pm 17.4$ & $78.2 \pm 13.9^{*}$ & $68.1 \pm 11.9^{* * *}$ \\
\hline Height (cm) & $165 \pm 6.3$ & $160 \pm 6.0^{*}$ & $160 \pm 6.5^{* *}$ \\
\hline $\mathrm{BMI}\left(\mathrm{kg} / \mathrm{m}^{2}\right)$ & $25.3 \pm 5.9$ & $30.6 \pm 4.6^{*}$ & $26.7 \pm 3.9^{* * *}$ \\
\hline Relative ASM $\left(\mathrm{kg} / \mathrm{m}^{2}\right)$ & $5.9 \pm 0.6$ & $6.1 \pm 0.7$ & $4.9 \pm 0.4^{* * * * * * *}$ \\
\hline TBLM (kg) & $37.4 \pm 3.9$ & $37.9 \pm 5.3$ & $31.1 \pm 3.3^{* * * * *}$ \\
\hline TBLM/weight & $0.56 \pm 0.11$ & $0.49 \pm 0.07^{*}$ & $0.47 \pm 0.07^{* *}$ \\
\hline TBFM (kg) & $28.2 \pm 14.5$ & $37.4 \pm 10.4^{*}$ & $33.4 \pm 9.7$ \\
\hline TBFM/weight & $0.38 \pm 0.11$ & $0.47 \pm 0.07^{*}$ & $0.48 \pm 0.07^{* *}$ \\
\hline \multicolumn{4}{|l|}{ Muscle strength } \\
\hline Grip strength (kg) & $27.5 \pm 5.1$ & $22.7 \pm 5.1^{*}$ & $19.9 \pm 3.4^{* * * * *}$ \\
\hline Knee extensor strength (kg) & $69.6 \pm 16.9$ & $52.7 \pm 16.5^{*}$ & $42.9 \pm 9.8^{* * * *}$ \\
\hline \multicolumn{4}{|l|}{ Physical activity } \\
\hline Energy expenditure (kcal/week) & $30837 \pm 7744$ & $25399 \pm 6125^{*}$ & $22645 \pm 6451^{* *}$ \\
\hline \multicolumn{4}{|l|}{ Men } \\
\hline \multicolumn{4}{|l|}{ Clinical variables } \\
\hline Age (years) & $33.0 \pm 3.8$ & $74.8 \pm 7.3^{*}$ & $78.9 \pm 6.8^{* * * * * *}$ \\
\hline Weight (kg) & $92.3 \pm 16.7$ & $89.7 \pm 15.6$ & $75.9 \pm 9.6^{* *, * * *}$ \\
\hline Height (cm) & $179 \pm 5.8$ & $175 \pm 6.0^{*}$ & $171 \pm 7.2^{* * * * * *}$ \\
\hline $\mathrm{BMI}\left(\mathrm{kg} / \mathrm{m}^{2}\right)$ & $28.8 \pm 4.7$ & $29.2 \pm 4.0$ & $26.0 \pm 2.4^{* * * * * *}$ \\
\hline Relative ASM $\left(\mathrm{kg} / \mathrm{m}^{2}\right)$ & $8.5 \pm 1.0$ & $7.9 \pm 0.4^{*}$ & $6.7 \pm 0.5^{* * * * * *}$ \\
\hline TBLM (kg) & $57.6 \pm 7.3$ & $54.7 \pm 4.2$ & $45.9 \pm 4.9^{* *, * * *}$ \\
\hline TBLM/weight & $0.63 \pm 0.08$ & $0.62 \pm 0.08$ & $0.61 \pm 0.07$ \\
\hline TBFM (kg) & $30.7 \pm 12.0$ & $31.6 \pm 12.5$ & $26.5 \pm 7.3^{* * *}$ \\
\hline TBFM/weight & $0.32 \pm 0.08$ & $0.34 \pm 0.08$ & $0.34 \pm 0.06$ \\
\hline \multicolumn{4}{|l|}{ Muscle strength } \\
\hline Grip strength (kg) & $50.4 \pm 9.5$ & $39.2 \pm 7.4^{*}$ & $33.7 \pm 7.4^{* * * * * *}$ \\
\hline Knee extensor strength (kg) & $122 \pm 33.7$ & $80.7 \pm 19.1^{*}$ & $61.7 \pm 16.8^{* * * * * *}$ \\
\hline \multicolumn{4}{|l|}{ Physical activity } \\
\hline Energy expenditure (kcal/week) & $40136 \pm 14350$ & $34222 \pm 9090^{*}$ & $27009 \pm 7008^{* * * * * *}$ \\
\hline
\end{tabular}

Values are presented as mean $\pm \mathrm{SD}$ and $p$ values

$B M I$ body mass index, ASM appendicular skeletal muscle mass, TBLM total body lean mass, TBFM total body fat mass

${ }^{*} p<0.05$ younger vs. older; ${ }^{* *} p<0.05$ younger vs. sarcopenic; ${ }^{* * *} p<0.05$ older vs. sarcopenic

TBLM $(p<0.01)$. Similarly, absolute $(12.9(8.6-17.5)$ versus $9.7(6.1-13.4))$ and relative propeptide concentrations were $>1.3$-fold higher in men than in women (both $p<0.01)$. Among younger subjects, men had nearly twofold higher myostatin levels as compared to younger women $(p<0.001)$ (Fig. $4 \mathrm{a})$; this difference was diminished after expressing myostatin relative to TBLM (Fig. 4b) but remained significant $(p<0.01)$. Similar observations were made for propeptide, with younger men having greater than twofold higher absolute concentrations
( $p<0.001$; Fig. 4c) and $42 \%$ higher relative concentrations than younger women $(p<0.05$; Fig. $4 d)$. In older subjects and sarcopenic older subjects, no differences in absolute myostatin or propeptide concentrations were observed between women and men (Fig. $4 \mathrm{a}$ and c, respectively). However, after adjusting for differences in TBLM, both older women and sarcopenic older women had 52 and $14 \%$ higher relative myostatin levels than the corresponding groups of men ( $p<0.001$ and 0.05 , respectively; Fig. $4 \mathrm{~b})$. Older women and sarcopenic older women also had 35 
Table 3 Biochemical parameters in younger, older and sarcopenic older women and men $(n=240)$

\begin{tabular}{|c|c|c|c|}
\hline & $\begin{array}{l}\text { Younger } \\
(n=40)\end{array}$ & $\begin{array}{l}\text { Older } \\
(n=40)\end{array}$ & $\begin{array}{l}\text { Sarcopenic } \\
(n=40)\end{array}$ \\
\hline \multicolumn{4}{|l|}{ Women } \\
\hline \multicolumn{4}{|l|}{ Biochemical variables } \\
\hline Myostatin (ng/mL) & $5.5(3.2-7.3)$ & $7.3(5.7-11.7)^{*}$ & $5.3(4.2-8.0)^{* * *}$ \\
\hline Myostatin/TBLM (ng/ml/kg) & $0.142(0.091-0.195)$ & $0.199(0.138-0.327)^{*}$ & $0.175(0.145-0.255)^{* *}$ \\
\hline Propeptide (ng/ml) & $7.1(5.2-10.8)$ & $11.4(7.3-20.1)^{*}$ & $10.0(6.5-12.4)^{* * *}$ \\
\hline Propeptide/TBLM (ng/ml/kg) & $0.194(0.139-0.294)$ & $0.292(0.186-0.203)^{*}$ & $0.307(0.203-0.417)^{* *}$ \\
\hline FLRG $(\mathrm{ng} / \mathrm{mL})$ & $5.1(4.3-6.0)$ & $7.3(6.2-9.7)^{*}$ & $8.3(6.7-10.6)^{* *}$ \\
\hline GASP1 (ng/mL) & $7.6(6.5-10.1)$ & $9.4(7.2-11.0)$ & $9.2(7.1-12.2)^{* *}$ \\
\hline Total 25-(OH)D (ng/mL) & $25.0(17.3-34.8)$ & $20.0(14.3-24.0)^{*}$ & $18.5(14.0-24.8)^{* *}$ \\
\hline IGF-1 (ng/mL) & $235(191-305)$ & $141(93-183)^{*}$ & $105(78-147)^{* * * * * *}$ \\
\hline IGF-2 (ng/mL) & $1160(958-1375)$ & $1112(933-1367)$ & $1167(884-1336)$ \\
\hline IGFBP-2 (ng/mL) & $406(190-621)$ & $447(308-775)$ & $635(539-987)^{* * * * * *}$ \\
\hline IGFBP-3 (ng/mL) & $4580(4099-5094)$ & $4096(3536-4513)^{*}$ & $3913(3171-4389)^{* *}$ \\
\hline Total $E_{1}(\mathrm{pg} / \mathrm{mL})$ & $47.0(33.3-57.8)$ & $31.0(19.0-37.0)^{*}$ & $23.0(16.0-29.0)^{* *}$ \\
\hline Total $E_{2}(\mathrm{pg} / \mathrm{mL})$ & $54.0(30.5-108.5)$ & $5.6(4.2-9.1)^{*}$ & $4.9(3.2-7.3)^{* *}$ \\
\hline Total T (ng/dL) & $23.5(18.0-30.0)$ & $16.0(12.0-24.0)^{*}$ & $21.0(11.0-30.0)$ \\
\hline Bio $E_{2}(p g / m L)$ & $15.0(8.2-28.2)$ & $2.1(1.0-3.2)^{*}$ & $1.0(0.6-1.7)^{* * * * * *}$ \\
\hline Bio T (ng/dL) & $1.5(0.9-2.1)$ & $1.5(1.0-2.6)$ & $1.1(0.7-1.8)^{* * *}$ \\
\hline SHBG (nmol/L) & $63.1(45.0-95.6)$ & $40.5(23.2-57.8)^{*}$ & $52.8(46.7-73.0)^{* * *}$ \\
\hline \multicolumn{4}{|l|}{ Men } \\
\hline \multicolumn{4}{|l|}{ Biochemical variables } \\
\hline Myostatin (ng/mL) & $10.5(9.0-14.4)$ & $7.1(5.4-8.8)^{*}$ & $6.9(4.4-8.9)^{* *}$ \\
\hline Myostatin/TBLM (ng/ml/kg) & $0.192(0.156-0.241)$ & $0.131(0.101-0.164)^{*}$ & $0.153(0.092-0.192)^{* *}$ \\
\hline Propeptide (ng/ml) & $15.7(11.7-19.4)$ & $11.8(7.6-15.7)$ & $10.8(6.4-14.9)^{* *}$ \\
\hline Propeptide/TBLM (ng/ml/kg) & $0.276(0.207-0.328)$ & $0.216(0.137-0.305)$ & $0.240(0.153-0.309)$ \\
\hline FLRG $(n g / m L)$ & $4.5(3.8-5.3)$ & $7.5(6.1-9.4)^{*}$ & $7.4(6.3-9.9)^{* *}$ \\
\hline GASP1 (ng/mL) & $9.4(7.5-10.6)$ & $9.4(7.3-10.7)$ & $10.3(8.9-11.9)$ \\
\hline Total 25-(OH)D (ng/mL) & $23.5(17.0-31.8)$ & $21.5(17.0-25.8)$ & $21.0(16.0-26.8)$ \\
\hline IGF-1 (ng/mL) & $344(292-446)$ & $193(114-245)^{*}$ & $169(103-245)^{* *}$ \\
\hline IGF-2 (ng/mL) & $1099(1005-1226)$ & $961(774-1075)^{*}$ & $964(785-1071)^{* *}$ \\
\hline IGFBP-2 (ng/mL) & $244(142-361)$ & $547(391-728)^{*}$ & $758(531-1049)^{* *}$ \\
\hline IGFBP-3 (ng/mL) & $4469(3833-4988)$ & $3202(2596-3581)^{*}$ & $3230(2613-4019)^{* * * * * *}$ \\
\hline Total $E_{1}(p g / m L)$ & $32.5(25.3-38.0)$ & $35.0(30.0-45.0)^{*}$ & $31.0(25.5-44.0)$ \\
\hline Total $E_{2}(p g / m L)$ & $23.0(19.0-30.0)$ & $25.0(20.0-28.0)$ & $23.0(18.0-29.0)$ \\
\hline Total T (ng/dL) & $462(392-549)$ & $424(321-526)$ & $484(388-609)$ \\
\hline Bio $E_{2}(p g / m L)$ & $12.8(11.0-17.5)$ & $9.5(7.1-11.0)^{*}$ & $7.4(5.5-10.0)^{* *}$ \\
\hline Bio $T$ (ng/dL) & $133(115-156)$ & $50.8(37.0-63.5)^{*}$ & $50.8(37.4-62.7)^{* *}$ \\
\hline SHBG (nmol/L) & $25.1(19.4-31.3)$ & $45.5(39.0-58.6)^{*}$ & $50.3(39.9-64.0)^{* *}$ \\
\hline
\end{tabular}

Values are presented as median (IQR)

TBLM total body lean mass, FLRG follistatin-related gene protein, GASP-1 growth and serum protein-1, 25(OH)D 25-hydroxyvitamin D, IGF insulin-like growth factor, IGFBP IGF-binding protein, $E_{1}$ estrone, $E_{2}$ estradiol, $T$ testosterone; $S H B G$ sex hormone-binding globulin

${ }^{*} p<0.05$ younger vs. older; ${ }^{* *} p<0.05$ younger vs. sarcopenic; ${ }^{* * *} p<0.05$ older vs. sarcopenic 


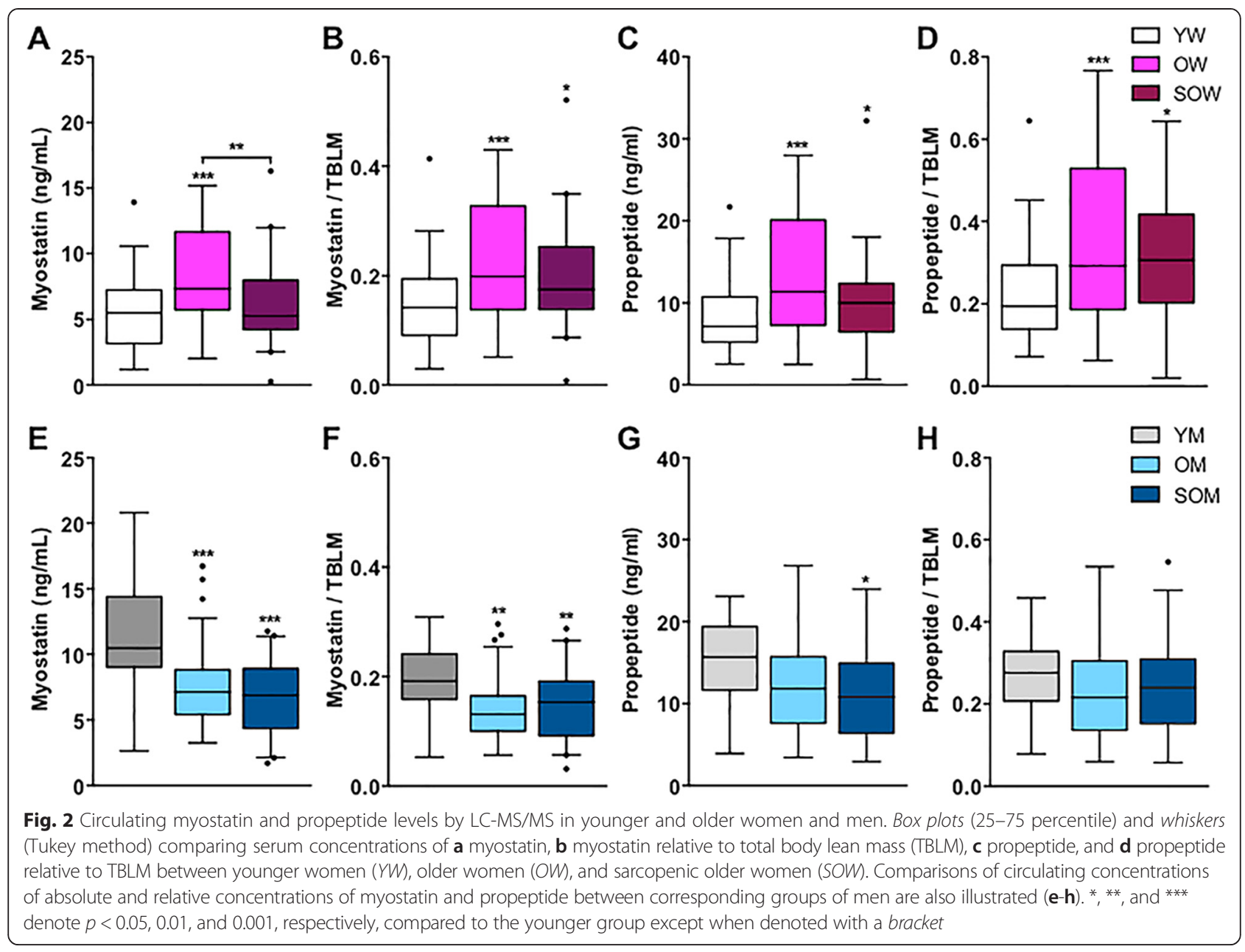

and $28 \%$ higher propeptide levels relative to TBLM than the corresponding groups of men $(p<0.01$ and 0.05 , respectively; Fig. 4d).

Given the differences in myostatin levels between women and men, we next examined whether circulating concentrations of FLRG and GASP-1 differed. In younger, older, and sarcopenic older groups, FLRG and GASP-1 levels were similar between women and men (Fig. 5a, b, respectively). In younger subjects, the ratios of FLRG and GASP-1 to myostatin were significantly higher in younger women as compared to younger men (both $p<0.001$; Fig. $5 \mathrm{c}$, d, respectively). In older and sarcopenic older subjects, there were no differences between women and men in the ratios of either FLRG or GASP-1 to myostatin.

Associations between myostatin and body composition, muscle strength, physical activity, and other circulating biochemical parameters

We next examined associations between circulating myostatin levels and body composition, muscle strength, and physical activity using age-adjusted correlations in women and men, separately (Table 4). Positive albeit weak correlations were observed between myostatin concentrations and relative ASM and TBLM in women and relative ASM in men (all $p<0.05$ ). Moreover, in men, a negative correlation was observed between myostatin and total body fat mass $(p<0.05)$. Myostatin also exhibited a significant correlation with grip strength $(p<0.05)$ and a positive trend with knee extensor strength $(p=0.073)$ in men but not in women. No correlations were observed between concentrations of myostatin and the amount of self-reported physical activity. Finally, correlations between myostatin and these clinical parameters are provided for the subgroups of younger, older, and older sarcopenic women and men in Additional files 4: Table S4 and 5: Table S5, respectively.

In women and men, myostatin levels exhibited modest age-adjusted correlations with FLRG (both $p<0.01$ ) and stronger correlations with GASP-1 (both $p<0.001$ ). Analysis of other circulating biochemical parameters revealed a negative correlation between myostatin and total testosterone and sex hormone-binding globulin in 


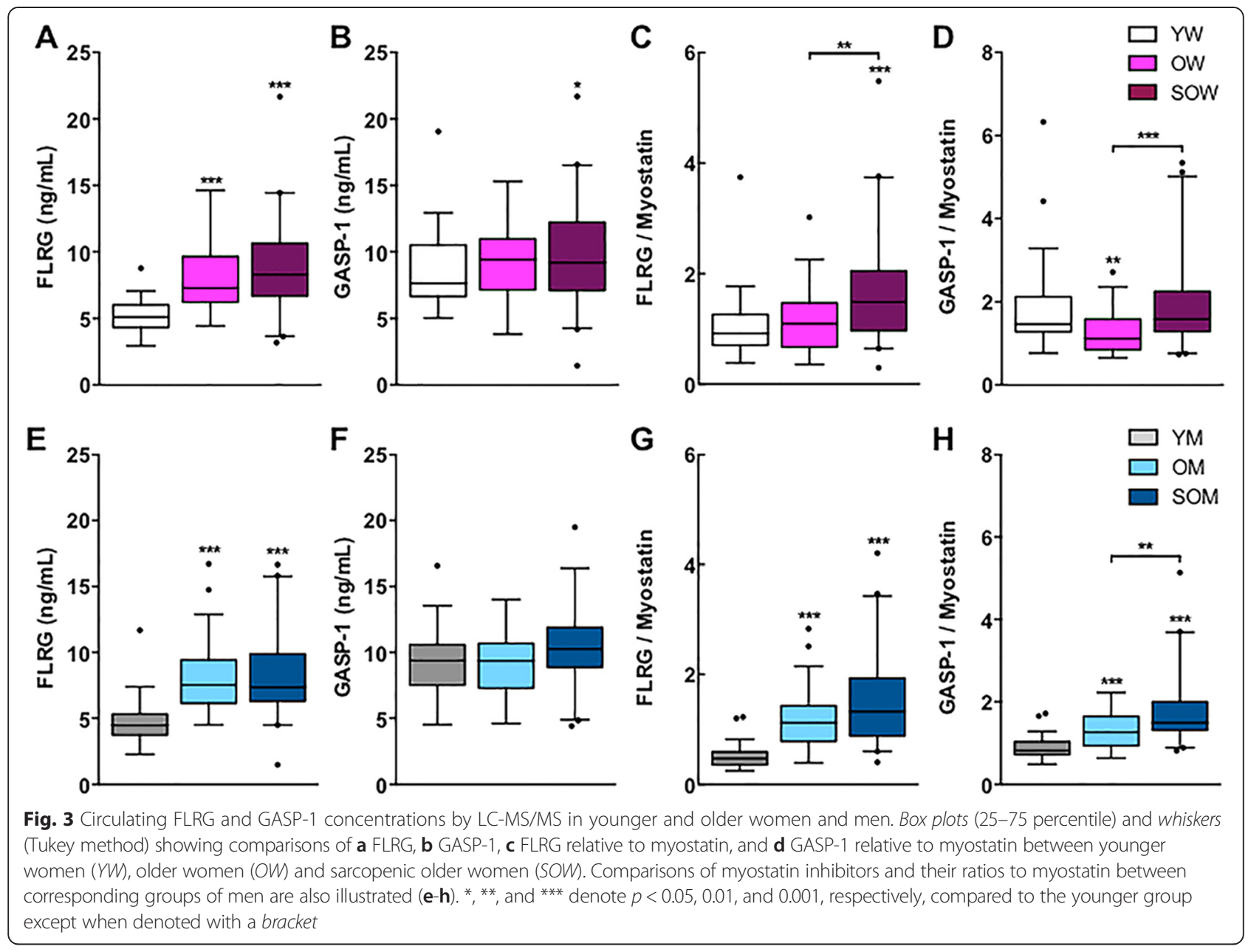

women ( $p<0.05$ and 0.001 , respectively). In men, myostatin had a positive association with bioavailable testosterone $(p<0.001$, respectively). No correlations were observed between myostatin and vitamin D or circulating components of the insulin-like growth factor (IGF) system, including IGF-1, IGF-2, IGF-binding protein (BP)-2, and IGFBP-3. Correlations between myostatin and the biochemical parameters are provided for the subgroups of younger, older, and older sarcopenic women and men in Additional files 4: Table S4 and 5: Table S5, respectively.

\section{Discussion}

In this study, we developed a highly specific and accurate multiplexed LC-MS/MS assay for measuring circulating concentrations of mature and propeptide forms of the muscle-derived protein, myostatin, and two of its inhibitors, FLRG and GASP-1, in human serum. Using this novel approach and a well-characterized populationbased sample, we show that absolute and relative concentrations of myostatin and propeptide are higher in younger men than younger women, increase with age in women, but in fact decrease with age in men. Intriguingly, these age-associated changes result in much higher circulating myostatin and propeptide concentrations per unit of lean mass in older women than older men. We also demonstrate that circulating concentrations of FLRG and, to a lesser extent, GASP-1 increase similarly in women and men with age, particularly in the context of sarcopenia. Finally, we report that circulating concentrations of myostatin exhibit positive, but not robust, age-adjusted correlations with relative ASM in both sexes.

As highlighted here and previously [31, 32], there are several challenges to the specific and accurate measurement of circulating myostatin concentrations using traditional antibody-based approaches, such as RIA, ELISA, and Western blotting. Through chromatographic separation and the use of peptide sequences, or "fingerprints," that are unique to and, in particular, distinct from GDF11, LC-MS/MS provides a highly specific method to quantify myostatin. Using this approach, we observed myostatin levels of $8.6 \pm 3.7 \mathrm{ng} / \mathrm{ml}$ in men and $6.7 \pm 3.3 \mathrm{ng} /$ $\mathrm{ml}$ in women. These concentrations are considerably lower 


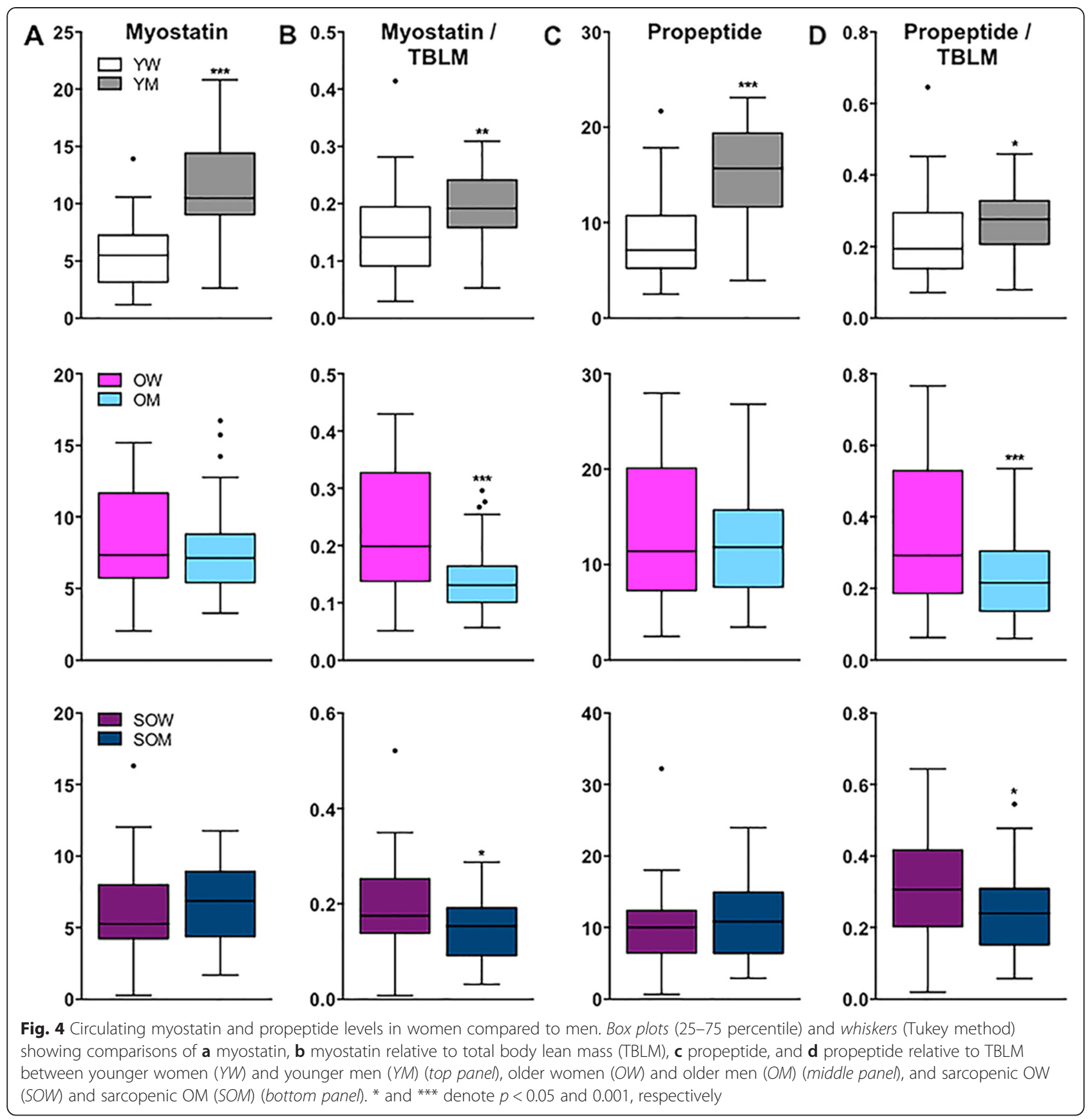

than the mean values $(26.7$ to $>100 \mathrm{ng} / \mathrm{ml}$ ) reported in several recent studies of healthy adults using commercial ELISA kits [16, 18, 19, 33-35] but similar to the results obtained in healthy adults using an ELISA comprised of proprietary and presumably more specific, reagents $([15,17]$. In addition to improved specificity, LC-MS/MS has better sensitivity for quantifying low abundance proteins than antibody-based approaches. By coupling immunopurification and LC-MS/MS, we observed both a LOD and a LOQ of $0.01 \mathrm{nM}$, or $0.248 \mathrm{ng}$, for myostatin. In comparison, Peiris et al. observed that the LOD for recombinant myostatin proteins by Western blot was $~ 83.33 \mathrm{nM}$, or 2000 ng [32]. We established similarly low LOD and LOQ values for propeptide, FLRG, and GASP-1. Therefore, this novel multiplexed LC-MS/MS assay offers a highly specific and sensitive means to quantify circulating concentrations of myostatin and myostatin-related proteins in a single small (400 ul) sample of human serum.

Myostatin is a promising therapeutic target to improve muscle health [36]. Several pharmacological approaches have been developed, including neutralizing antibodies, propeptides, soluble decoy receptors, and receptor 


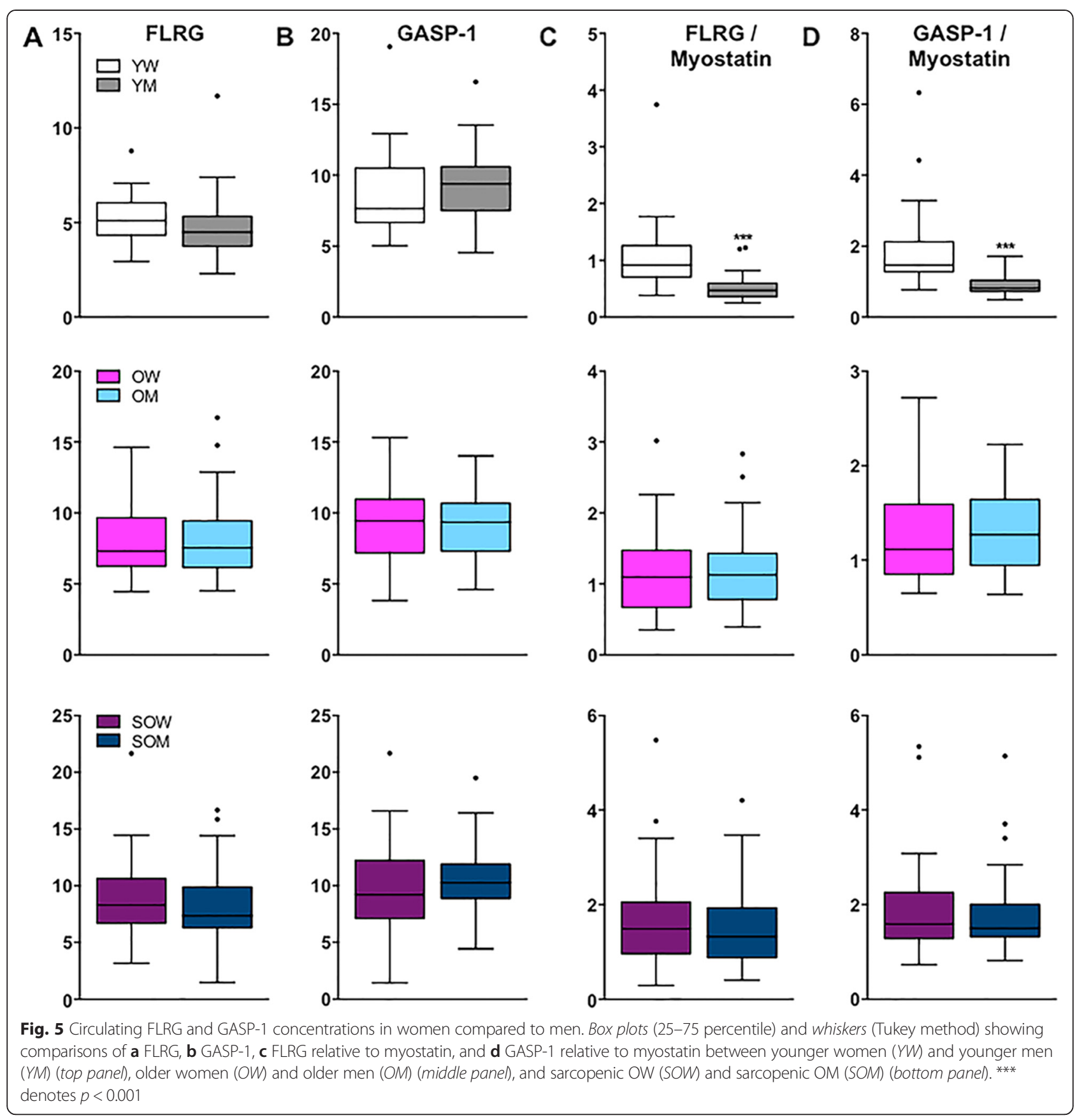

antagonists. Such interventions have been shown to increase skeletal muscle mass and improve parameters of strength and physical function in preclinical models of aging and disease [12, 37, 38]. A number of early phase clinical trials are underway $[36,39]$. It is therefore surprising then, that relatively little is known about the relationship between circulating myostatin concentrations and skeletal muscle mass in human conditions associated with its loss or degeneration. Indeed such data could inform the selection of indications or individuals that may be most responsive to targeted interventions.
In the present study, we demonstrate contrasting ageassociated changes in myostatin and propeptide levels in women and men. Specifically, we observed higher absolute and relative circulating concentrations in older women compared to younger women and lower concentrations in older men compared to younger men. Unexpectedly, we also measured higher concentrations of myostatin and propeptide per unit of lean mass in older women and sarcopenic older women than in corresponding groups of men. The prevalence of sarcopenia is higher in women than men; however, we can only 
Table 4 Age-adjusted Spearman correlations between circulating myostatin levels and body composition, muscle strength, physical activity and biochemical parameters in women and men

\begin{tabular}{|c|c|c|c|c|}
\hline \multirow[t]{2}{*}{ Variable } & \multicolumn{2}{|c|}{ Women $(n=120)$} & \multicolumn{2}{|c|}{ Men $(n=120)$} \\
\hline & $r$ & $p$ value & $r$ & $p$ value \\
\hline \multicolumn{5}{|l|}{ Body composition } \\
\hline BMI $\left(\mathrm{kg} / \mathrm{m}^{2}\right)$ & 0.08 & 0.414 & -0.11 & 0.250 \\
\hline Relative ASM $\left(\mathrm{kg} / \mathrm{m}^{2}\right)$ & 0.24 & 0.010 & 0.24 & 0.008 \\
\hline TBLM (kg) & 0.21 & 0.024 & 0.09 & 0.339 \\
\hline TBLM/weight & -0.03 & 0.772 & 0.26 & 0.005 \\
\hline TBFM (kg) & 0.05 & 0.585 & -0.20 & 0.026 \\
\hline TBFM/weight & 0.05 & 0.642 & -0.27 & 0.003 \\
\hline \multicolumn{5}{|l|}{ Muscle strength } \\
\hline Grip strength (kg) & 0.11 & 0.239 & 0.20 & 0.026 \\
\hline Knee extensor strength (kg) & 0.12 & 0.211 & 0.17 & 0.073 \\
\hline \multicolumn{5}{|l|}{ Physical activity } \\
\hline Energy expenditure (kcal/d) & -0.01 & 0.928 & -0.08 & 0.376 \\
\hline \multicolumn{5}{|l|}{ Biochemical parameters } \\
\hline FLRG (ng/mL) & 0.28 & 0.002 & 0.26 & 0.004 \\
\hline GASP1 (ng/mL) & 0.53 & $<0.001$ & 0.57 & $<0.001$ \\
\hline Total 25-(OH)D (ng/mL) & -0.04 & 0.701 & -0.05 & 0.575 \\
\hline IGF-1 (ng/mL) & -0.02 & 0.871 & -0.06 & 0.515 \\
\hline IGF-2 (ng/mL) & -0.17 & 0.072 & -0.09 & 0.315 \\
\hline IGFBP-2 (ng/mL) & -0.14 & 0.132 & -0.07 & 0.439 \\
\hline IGFBP-3 (ng/mL) & -0.15 & 0.115 & -0.07 & 0.464 \\
\hline Total $\mathrm{E}_{1}(\mathrm{pg} / \mathrm{mL})$ & 0.03 & 0.777 & 0.09 & 0.309 \\
\hline Total $E_{2}(p g / m L)$ & 0.02 & 0.843 & 0.03 & 0.778 \\
\hline Total T (ng/dL) & -0.20 & 0.027 & 0.18 & 0.056 \\
\hline Bioavailable $\mathrm{E}_{2}(\mathrm{pg} / \mathrm{mL})$ & 0.11 & 0.272 & 0.13 & 0.158 \\
\hline Bioavailable T (ng/dL) & 0.12 & 0.188 & 0.32 & $<0.001$ \\
\hline SHBG (nmol/L) & -0.29 & 0.001 & -0.13 & 0.170 \\
\hline
\end{tabular}

Values are presented as Spearman correlation coefficients $(r)$ and $p$ values $B M I$ body mass index, ASM appendicular skeletal muscle mass, TBLM total body lean mass, TBFM total body fat mass, FLRG follistatin-related gene protein, GASP-1 growth and serum protein-1, 25(OH)D 25-hydroxyvitamin D, IGF i nsulin-like growth factor, IGFBP insulin-like growth factor binding protein, $E_{1}$ estrone, $E_{2}$ estradiol, $T$ testosterone, SHBG sex hormone-binding globulin

speculate that myostatin plays a causal role in ageassociated muscle loss in women and that women may be more responsive than men to anti-myostatin therapies. In both sexes, we failed to see meaningful differences in myostatin concentrations or the ratio of myostatin to propeptide between older subjects and sarcopenic older subjects. Of note, we studied healthy older persons without chronic diseases associated with the deterioration of skeletal muscle, including cancer, chronic heart failure, chronic obstructive pulmonary disease, diabetes, chronic kidney disease, and human immunodeficiency virus. Future research is needed to determine the extent to which myostatin concentrations, or the ratio of myostatin to propeptide, are associated with skeletal muscle mass and function in the context of such conditions.

In 1962, Bullough and Lawrence first proposed that "diffusible substances," or chalones, regulate the mass of the specific tissue from which they were derived [1, 40]. Shortly after its discovery as a protein synthesized and secreted by skeletal muscle, Lee and McPherron highlighted the potential for myostatin to be a muscle chalone [41]. As a chalone, myostatin may be an evolutionarily conserved mechanism that was selected to prevent the allocation of limited resources to the further development and maintenance of the tissue from which it is derived. In younger women, this may have been critical for reproduction. Consistent with the concept of antagonistic pleiotropy, this early life benefit of myostatin may have later life costs, namely, the excessive deterioration of skeletal muscle. With the significant extension in life expectancy beyond the menopause, it is plausible that counter regulatory mechanisms could not be selected for and, consequently, myostatin contributes to the age-associated loss of skeletal muscle in women. In men on the other hand, myostatin is highest in younger men with the greatest muscle mass and, as would be anticipated for a chalone, lowest in older men with the least muscle mass. This same pattern is observed for sclerostin, which is synthesized in and secreted by osteocytes. Sclerostin functions as a potent negative regulator of the Wnt/ $\beta$-catenin signaling pathway to inhibit bone formation [42]. Serum sclerostin levels are positively associated with total body bone mass in both women and men [43]. The reason for sexually dimorphic age-related changes in myostatin is unclear. We observed that FLRG and GASP-1 are higher in younger women than younger men and increase with age in both sexes and even more so in those who are sarcopenic. This is the first report of FLRG and GASP-1 serum concentrations in women; however, in a smaller study using ELISAs, Ratvekius et al. observed no differences or trends for a decrease in FLRG and GASP-1 in older men compared to younger men. Furthermore, our data fail to show meaningful relationships between circulating myostatin concentrations in women and established mediators of skeletal muscle mass, including bioavailable testosterone, IGF-1, and IGF-2. In men, we observed positive, not negative, associations between circulating myostatin and bioavailable estrogen and testosterone concentrations. Additional research is needed to further understand what factors regulate myostatin abundance and/or activity and how such factors are affected by aging in both women and men.

Our study provides important insights into age-related changes and sex differences in the circulating concentrations of myostatin and its related proteins in healthy adults. However, it is important to recognize the cross- 
sectional design of our study. Longitudinal studies are needed to better define the relationships between myostatin, propeptide, FLRG and GASP-1 and age- and disease-related changes in skeletal muscle mass and performance, and the utility of these proteins as a biomarkers of current and future muscle health. Our sample was also predominantly white, and underrepresented with respect to persons of African, Asian, Hispanic, Latino, American Indian, and Alaskan Native ancestry groups. To our knowledge, the influence of origin on myostatin concentrations has not been investigated. Furthermore, our assay has notable strengths, including the ability to precisely monitor four analytes in a single sample of merely $400 \mathrm{ul}$ of serum. However, while we can specifically monitor the abundance of C-terminal (mature) and N-terminal (propeptide) regions unique to myostatin, at this time, we are not able to define the stoichiometry of free (active) versus bound (latent) forms in vivo. Of note, we did attempt an acid activation step in pooled serum to overcome this hurdle; however, we had reduced recovery of all proteins with the exception of propeptide, which did not change. We therefore chose to immunoprecipitate under physiological conditions without acid activation. Even so, we believe this multiplexed LC-MS/MS approach represents the current upper limit of specificity and sensitivity for assessing myostatin, propeptide, FLRG, and GASP-1 in human clinical samples, and that our study represents the most comprehensive assessment of these proteins in both women and men to date.

\section{Conclusions}

We have developed a highly specific and sensitive LC-MS/MS-based method for measuring concentrations of myostatin, propeptide, FLRG, and GASP-1 in a single small volume of human serum. We propose that (1) the age-associated increase in myostatin levels in women may contribute to their lower muscle mass and higher prevalence of sarcopenia relative to men; (2) myostatin acts as a homeostatic regulator of muscle mass in men, that is, the age-related loss of muscle in men is coupled with a decrease in myostatin and an increase in its inhibitors; (3) FLRG and GASP-1 increase with age and in the context of sarcopenia to inhibit the catabolic actions of myostatin; and (4) circulating concentrations of myostatin provide a significant, albeit weak biomarker of muscle mass in relatively healthy adult women and men. This novel method will enable future studies to determine the extent to which circulating concentrations of myostatin and its inhibitors change in the context of conditions associated with muscle loss or degeneration and, potentially, help identify individuals and conditions that will best respond to therapies that block myostatin signaling.

\section{Additional files}

Additional file 1: Table S1. Intra-assay precision of five replicate measures of recombinant myostatin, propeptide FLRG, and GASP-1 at four concentrations diluted in $5 \%$ bovine serum albumin in phosphate buffered saline. A pooled human serum sample was also analyzed.

Additional file 2: Table S2. Inter-assay variability for immunoaffinity purification and LC-MS/MS measures of recombinant myostatin, propeptide, FLRG, and GASP-1. Proteins were diluted together at the indicated concentrations in $5 \%$ bovine serum albumin in phosphate buffered saline. Measures were performed five times over a period of 21 days. A pooled human serum sample was analyzed similarly.

Additional file 3: Table S3. Percent recovery of myostatin, FLRG, and GASP-1. A human serum pool was spiked (+) at two concentrations (CONC) of the given analyte, and the percent recovery was determined relative to the calculated value of the endogenous level plus the spiked protein.

Additional file 4: Table S4. Spearman correlations between circulating myostatin levels and body composition, muscle strength, physical activity, and biochemical parameters in women.

Additional file 5: Table S5. Spearman correlations between circulating myostatin levels and body composition, muscle strength, physical activity, and biochemical parameters in men.

\section{Competing interests}

HRB, JNF, PMV, EJA, TAW, and RJS declare that they have no competing interests. SK has served on scientific advisory boards for Amgen and Bone Therapeutics. NKL has received speaker and/or consulting fees from Sanofi, Lilly, and GlaxoSmithKline and is participating in a clinical trial sponsored by Novartis.

\section{Authors' contributions}

The study was designed by HRB, TAW, RS, SK, and NKL. Data was collected by HRB and PMV and analyzed by HRB, PMV, JNF, EJA, and NKL. Data was interpreted by HRB, JNF, RS, SK, and NKL. The manuscript was drafted by $H R B, J N F, E J A$, and NKL and revised by HRB, JNF, PMV, EJA, TAW, RS, SK, and NKL. All authors read and approved the final manuscript.

\section{Acknowledgements}

We thank the women and men for their participation in this study. We also thank Sara J. Achenbach for data management and Linda M. Benson and Olga P. Bondar who both contributed to assay development. This work was supported in part by P01 AG004875 from the National Institute of Aging, R01 AR027065 from the National Institute of Arthritis and Musculoskeletal and Skin Diseases, the Pritzker Foundation, and generous gifts from the Hoeft Family and Robert and Arlene Kogod. Dr. Farr is supported by a career development award from the Robert and Arlene Kogod Center on Aging. This study was also supported by the Mayo Clinical Center for Clinical and Translational Science (CCaTS), Grant Number UL1 TR000135 from the National Center for Advancing Translational Science (NCATS), a component of the National Institutes of Health $(\mathrm{NIH})$. Its contents are solely the responsibility of the authors and do not necessarily represent the official view of $\mathrm{NIH}$.

\section{Author details}

${ }^{1}$ Department of Biochemistry and Molecular Biology, Mayo Clinic College of Medicine, Rochester, MN 55905, USA. ${ }^{2}$ Medical Genome Facility-Proteomics Core, Mayo Clinic College of Medicine, Rochester, MN 55905, USA. ${ }^{3}$ Division of Endocrinology, Department of Medicine, Mayo Clinic College of Medicine, Rochester, MN 55905, USA. ${ }^{4}$ Robert and Arlene Kogod Center on Aging, Mayo Clinic College of Medicine, Rochester, MN 55905, USA. ${ }^{5}$ Division of Biomedical Statistics and Informatics, Department of Health Sciences Research, Mayo Clinic College of Medicine, Rochester, MN 55905, USA. ${ }^{6}$ Department of Laboratory Medicine and Pathology, Mayo Clinic College of Medicine, Rochester, MN 55905, USA. 7Department of Physical Medicine and Rehabilitation, Mayo Clinic College of Medicine, 200 First Street SW, Rochester, MN 55905, USA. 
Received: 7 April 2015 Accepted: 29 May 2015

\section{Published online: 15 July 2015}

\section{References}

1. Bullough WS. The control of mitotic activity in adult mammalian tissues. Biol Rev Camb Philos Soc. 1962;37:307-42.

2. McPherron AC, Lawler AM, Lee SJ. Regulation of skeletal muscle mass in mice by a new TGF-beta superfamily member. Nature. 1997;387:83-90.

3. Sharma M, Kambadur R, Matthews KG, Somers WG, Devlin GP, Conaglen JV, et al. Myostatin, a transforming growth factor-beta superfamily member, is expressed in heart muscle and is upregulated in cardiomyocytes after infarct. J Cell Physiol. 1999;180(1):1-9. doi:10.1002/(SICI)10974652(199907)180:1<1::AID-JCP1>3.0.CO;2-V.

4. Anderson SB, Goldberg AL, Whitman M. Identification of a novel pool of extracellular pro-myostatin in skeletal muscle. J Biol Chem. 2008;283:7027-35.

5. McFarlane C, Langley B, Thomas M, Hennebry A, Plummer E, Nicholas G, et al. Proteolytic processing of myostatin is auto-regulated during myogenesis. Dev Biol. 2005;283(1):58-69. doi:10.1016/j.ydbio.2005.03.039.

6. Wolfman NM, McPherron AC, Pappano WN, Davies MV, Song K, Tomkinson $\mathrm{KN}$, et al. Activation of latent myostatin by the BMP-1/tolloid family of metalloproteinases. Proc Natl Acad Sci U S A. 2003;100(26):15842-6. doi:10.1073/pnas.2534946100.

7. Sartori R, Milan G, Patron M, Mammucari C, Blaauw B, Abraham R, et al. Smad 2 and 3 transcription factors control muscle mass in adulthood. Am J Physiol Cell Physiol. 2009;296(6):C1248-57. doi:10.1152/ajpcell.00104.2009.

8. Trendelenburg AU, Meyer A, Rohner D, Boyle J, Hatakeyama S, Glass DJ. Myostatin reduces Akt/TORC1/p70S6K signaling, inhibiting myoblast differentiation and myotube size. Am J Physiol Cell Physiol. 2009;296(6):C1258-70. doi:10.1152/ajpcell.00105.2009.

9. McPherron AC, Lee SJ. Double muscling in cattle due to mutations in the myostatin gene. Proc Natl Acad Sci U S A. 1997;94(23):12457-61.

10. Shelton GD, Engvall E. Gross muscle hypertrophy in whippet dogs is caused by a mutation in the myostatin gene. Neuromuscul Disord. 2007;17:721-2.

11. Whittemore LA, Song K, Li X, Aghajanian J, Davies M, Girgenrath S, et al. Inhibition of myostatin in adult mice increases skeletal muscle mass and strength. Biochem Biophys Res Commun. 2003;300(4):965-71.

12. LeBrasseur NK, Schelhorn TM, Bernardo BL, Cosgrove PG, Loria PM, Brown TA. Myostatin inhibition enhances the effects of exercise on performance and metabolic outcomes in aged mice. J Gerontol A Biol Sci Med Sci. 2009;64(9):940-8. doi:10.1093/gerona/glp068.

13. Attie KM, Borgstein NG, Yang Y, Condon CH, Wilson DM, Pearsall AE, et al. A single ascending-dose study of muscle regulator ACE-031 in healthy volunteers. Muscle Nerve. 2013;47(3):416-23. doi:10.1002/mus.23539.

14. Yarasheski KE, Bhasin S, Sinha-Hikim I, Pak-Loduca J, Gonzalez-Cadavid NF. Serum myostatin-immunoreactive protein is increased in 60-92 year old women and men with muscle wasting. J Nutr Health Aging. 2002;6(5):343-8.

15. Ratkevicius A, Joyson A, Selmer I, Dhanani T, Grierson C, Tommasi AM, et al. Serum concentrations of myostatin and myostatin-interacting proteins do not differ between young and sarcopenic elderly men. J Gerontol A Biol Sci Med Sci. 2011;66(6):620-6. doi:10.1093/gerona/glr025.

16. Szulc P, Schoppet M, Goettsch C, Rauner M, Dschietzig T, Chapurlat R, et al. Endocrine and clinical correlates of myostatin serum concentration in men—the STRAMBO study. J Clin Endocrinol Metab. 2012;97(10):3700-8. doi:10.1210/jc.2012-1273.

17. Lakshman KM, Bhasin S, Corcoran C, Collins-Racie LA, Tchistiakova L, Forlow $\mathrm{SB}$, et al. Measurement of myostatin concentrations in human serum: circulating concentrations in young and older men and effects of testosterone administration. Mol Cell Endocrinol. 2009;302(1):26-32. doi:10.1016/j.mce.2008.12.019.

18. Saremi A, Gharakhanloo R, Sharghi S, Gharaati MR, Larijani B, Omidfar K. Effects of oral creatine and resistance training on serum myostatin and GASP-1. Mol Cell Endocrinol. 2010;317(1-2):25-30. doi:10.1016/ j.mce.2009.12.019

19. Chen MJ, Han DS, Yang JH, Yang YS, Ho HN, Yang WS. Myostatin and its association with abdominal obesity, androgen and follistatin levels in women with polycystic ovary syndrome. Hum Reprod. 2012;27(8):2476-83. doi:10.1093/humrep/des209.

20. White TA, LeBrasseur NK. Myostatin and sarcopenia: opportunities and challenges—a mini-review. Gerontology. 2014;60(4):289-93. doi:10.1159/ 000356740 .
21. Nakashima M, Toyono T, Akamine A, Joyner A. Expression of growth/ differentiation factor 11, a new member of the BMP/TGFbeta superfamily during mouse embryogenesis. Mech Dev. 1999;80(2):185-9.

22. Hill JJ, Davies MV, Pearson AA, Wang JH, Hewick RM, Wolfman NM, et al. The myostatin propeptide and the follistatin-related gene are inhibitory binding proteins of myostatin in normal serum. J Biol Chem. 2002;277(43):40735-41. doi:10.1074/jbc.M206379200.

23. Hill JJ, Qiu Y, Hewick RM, Wolfman NM. Regulation of myostatin in vivo by growth and differentiation factor-associated serum protein-1: a novel protein with protease inhibitor and follistatin domains. Mol Endocrinol. 2003;17(6):1144-54. doi:10.1210/me.2002-0366.

24. Lebrasseur NK, Achenbach SJ, Melton 3rd LJ, Amin S, Khosla S. Skeletal muscle mass is associated with bone geometry and microstructure and serum insulin-like growth factor binding protein-2 levels in adult women and men. J Bone Miner Res. 2012;27(10):2159-69. doi:10.1002/ jbmr.1666.

25. Fielding RA, Vellas B, Evans WJ, Bhasin S, Morley JE, Newman AB, et al. Sarcopenia: an undiagnosed condition in older adults. Current consensus definition: prevalence, etiology, and consequences. International working group on sarcopenia. J Am Med Dir Assoc. 2011;12(4):249-56. doi:10.1016/ j.jamda.2011.01.003.

26. Melton III LJ, Riggs BL, Achenbach SJ, Amin S, Camp JJ, Rouleau PA, et al. Does reduced skeletal loading account for age-related bone loss? J Bone Miner Res. 2006;21(12):1847-55.

27. Paffenbarger Jr RS, Wing AL, Hyde RT. Physical activity as an index of heart attack risk in college alumni. Am J Epidemiol. 1978;108(3):161-75.

28. Ainsworth BE, Haskell WL, Whitt MC, Irwin ML, Swartz AM, Strath SJ, et al. Compendium of physical activities: an update of activity codes and MET intensities. Med Sci Sports Exerc. 2000;32(9 Suppl):S498-504.

29. Khosla S, Melton III LJ, Atkinson EJ, O'Fallon WM, Klee GG, Riggs BL. Relationship of serum sex steroid levels and bone turnover markers with bone mineral density in men and women: a key role for bioavailable estrogen. J Clin Endocrinol Metab. 1998;83(7):2266-74.

30. Khosla S, Amin S, Singh RJ, Atkinson EJ, Melton 3rd LJ, Riggs BL. Comparison of sex steroid measurements in men by immunoassay versus mass spectroscopy and relationships with cortical and trabecular volumetric bone mineral density. Osteoporos Int. 2008;19(10):1465-71. doi:10.1007/ s00198-008-0591-5.

31. White TA, Lebrasseur NK. Myostatin and sarcopenia: opportunities and challenges—a mini-review. Gerontology. 2014. doi:10.1159/000356740.

32. Peiris HN, Ashman K, Vaswani K, Kvaskoff D, Rice GE, Mitchell MD. Method development for the detection of human myostatin by high-resolution and targeted mass spectrometry. J Proteome Res. 2014. doi:10.1021/pr5004642.

33. Han DS, Chen YM, Lin SY, Chang HH, Huang TM, Chi YC, et al. Serum myostatin levels and grip strength in normal subjects and patients on maintenance haemodialysis. Clin Endocrinol (Oxf). 2011;75(6):857-63. doi:10.1111/j.1365-2265.2011.04120.x.

34. Wintgens KF, Dschietzig T, Stoeva S, Paulsson M, Armbruster FP. Plasma myostatin measured by a competitive ELISA using a highly specific antiserum. Clinica Chimica Acta; Int J Clinical Chemistry. 2012;413 (15-16):1288-94. doi:10.1016/j.cca.2012.04.023.

35. Diel P, Schiffer T, Geisler S, Hertrampf T, Mosler S, Schulz S, et al. Analysis of the effects of androgens and training on myostatin propeptide and follistatin concentrations in blood and skeletal muscle using highly sensitive immuno PCR. Mol Cell Endocrinol. 2010;330(1-2):1-9. doi:10.1016/j.mce.2010.08.015.

36. Jasuja R, LeBrasseur NK. Regenerating skeletal muscle in the face of aging and disease. Am J Phys Med Rehabil. 2014;93(11 Suppl 3):S88-96. doi:10.1097/PHM.0000000000000118.

37. Bogdanovich S, Krag TO, Barton ER, Morris LD, Whittemore LA, Ahima RS, et al. Functional improvement of dystrophic muscle by myostatin blockade. Nature. 2002;420(6914):418-21. doi:10.1038/nature01154.

38. Zhang L, Rajan V, Lin E, Hu Z, Han HQ, Zhou X, et al. Pharmacological inhibition of myostatin suppresses systemic inflammation and muscle atrophy in mice with chronic kidney disease. FASEB J. 2011;25(5):1653-63. doi:10.1096/fj.10-176917.

39. Smith RC, Lin BK. Myostatin inhibitors as therapies for muscle wasting associated with cancer and other disorders. Curr Opin Support Palliat Care. 2013;7(4):352-60. doi:10.1097/SPC.0000000000000013.

40. Bullough WS. The actions of the chalones. Agents Actions. 1971;2(1):1-7.

41. Lee SJ, McPherron AC. Myostatin and the control of skeletal muscle mass. Curr Opin Genet Dev. 1999;9(5):604-7. 
42. Khosla S, Westendorf JJ, Oursler MJ. Building bone to reverse osteoporosis and repair fractures. J Clin Invest. 2008;1 18:421-8.

43. Modder UI, Hoey KA, Amin S, McCready LK, Achenbach SJ, Riggs BL,

et al. Relation of age, gender, and bone mass to circulating

sclerostin levels in women and men. J Bone Miner

Res. 2011;26(2):373-9.

Submit your next manuscript to BioMed Central and take full advantage of:

- Convenient online submission

- Thorough peer review

- No space constraints or color figure charges

- Immediate publication on acceptance

- Inclusion in PubMed, CAS, Scopus and Google Scholar

- Research which is freely available for redistribution 